\title{
HIGH EFFICIENCY DIESEL ENGINE CONCEPT WITH VARIABLE VALVE TRAIN AND CYLINDER DEACTIVATION FOR INTEGRATION INTO A TRACTOR
}

\author{
Matthias Thees*, Thomas Buitkamp*, \\ Michael Guenthner* \\ * Institute of Vehicle Propulsion Systems (LAF), \\ University of Kaiserslautern/Germany (TUK)
}

\author{
Peter Pickel** \\ ** John Deere GmbH \& Co. KG ETIC, \\ Kaiserslautern/Germany
}

\begin{abstract}
The objective of current research on internal combustion engines is to further reduce exhaust emissions while simultaneously reducing fuel consumption. The resulting measures often mean an increase in complexity of internal combustion engines, which on one hand increases production cost and on the other hand increases the susceptibility of the overall system to defects. It is therefore necessary to develop technologies which can generate an advantage for the consumer despite increasing complexity. Within the scope of the project "High Efficiency Diesel Engine Concept" ("Hocheffizientes Diesel-Motoren-Konzept" HDMK), funded by the Federal Ministry of Economic Affairs and Energy with TÜV Rheinland as project management organization (funding code: 19U15003A), two engine concepts were investigated and combined on a John Deere four-cylinder inline engine.
\end{abstract}

On the one hand, a new cylinder activation concept ("3/4cylinder concept") was implemented with the aim of reducing fuel consumption. On the other hand, a fully variable valve train was developed for this engine, which both improves the functionality of the 3/4-cylinder concept and can have a positive influence on exhaust emissions through internal exhaust gas recirculation.

A comparison of this engine concept with its series reference based on measurement data showed a fuel economy advantage of up to $5.2 \%$ in the low load field cycles of the DLG PowerMix. The maximum fuel consumption benefit in the low load engine regime exceeded $15 \%$ in some of the operating points.

As a final step, the engine was modified for the integration into an existing and working tractor, maintaining the available installation space of the powertrain.

\section{INTRODUCTION}

Reaching climate objectives is one of the most important issues of the 21st century. To achieve climate goals, society should avoid anthropogenic emissions with greenhouse effect. Every part of society dealing with energy conversion and use is affected by anthropogenic emissions. For the mobility sector, reducing emissions is of special importance, particularly the reduction of greenhouse gases such as carbon dioxide $\left(\mathrm{CO}_{2}\right)$. In the long term, $\mathrm{CO}_{2}$ neutral mobility could be realized by using regenerative energy through sustainable electricity and/or realizing a closed carbon cycle (e.g. by recycling of carbon from exhaust gases). However, in the short term, other approaches are necessary for the mobility sector, e.g. increasing engine efficiency to reduce $\mathrm{CO}_{2}$-emission [1].

The objective of the "HDMK" project is to increase the efficiency of a non-road commercial vehicle diesel engine. The vehicle integration of the engine is the final stage of the investigation and provides a realistic outlook on the practical application of the investigated engine concepts. For this purpose, a John Deere 6135 tractor equipped with a 4-cylinder in-line diesel engine was used. The engine uses a common-rail injection system and dual turbocharging. Table 1 shows a summary of technical details of the base engine. The base engine complies with the EU stage IV emission standard (see Table 2), which compares to US TIER 4 emission standard. 
TABLE 1: TECHNICAL DETAILS OF BASE ENGINE [2]

\begin{tabular}{|l|l|l|}
\hline & value & unit \\
\hline maximum effective power & 130 & $\mathrm{~kW}$ \\
\hline maximum torque (@1600 rpm) & 703 & $\mathrm{Nm}$ \\
\hline nominal speed & 2100 & $\mathrm{rpm}$ \\
\hline displacement & 4,5 & $\mathrm{dm}^{3}$ \\
\hline compression ratio & $17,3: 1$ & - \\
\hline bore diameter & 106.5 & $\mathrm{~mm}$ \\
\hline stroke & 127.0 & $\mathrm{~mm}$ \\
\hline firing order & $1-3-4-2$ & $(\mathrm{cyl}$. no.) \\
\hline valves per cylinder & 4 & - \\
\hline emission standard & EU stage IV & - \\
\hline
\end{tabular}

TABLE 2: EU STAGE IV EMISSION STANDARD [3]

\begin{tabular}{|l|l|l|}
\hline & $\begin{array}{l}56 \mathrm{~kW}<\mathrm{P}< \\
130 \mathrm{~kW}\end{array}$ & $\begin{array}{l}130 \mathrm{~kW}<\mathrm{P}< \\
560 \mathrm{~kW}\end{array}$ \\
\hline $\mathrm{CO}(\mathrm{g} / \mathrm{kWh})$ & 5.0 & 3.5 \\
\hline $\mathrm{HC}(\mathrm{g} / \mathrm{kWh})$ & 0.19 & 0.19 \\
\hline $\mathrm{NO}(\mathrm{g} / \mathrm{kWh})$ & 0.4 & 0.4 \\
\hline $\mathrm{PM}(\mathrm{g} / \mathrm{kWh})$ & 0.025 & 0.025 \\
\hline
\end{tabular}

\section{ENGINE CONCEPT "HDMK"}

The effective efficiency of a combustion engine can be characterized starting from the ideal efficiency and then subsequently considering the efficiency losses of the real process. For maximizing effective efficiency, these losses have to be minimized. Losses can be divided into 5 types:

- $\quad$ efficiency loss of real charge $\left(\eta_{\text {rch }}\right)$

- $\quad$ efficiency loss of real combustion $\left(\eta_{\mathrm{rc}}\right)$

- $\quad$ efficiency loss of wall heat transfer $\left(\eta_{\text {wht }}\right)$

- efficiency loss of real gas exchange $\left(\eta_{\text {rge }}\right)$

- $\quad$ efficiency loss of friction $\left(\eta_{\mathrm{fr}}\right)$

For reduction of heat transfer and charge exchange losses, a new concept is used which will be referred to as the "HDMK" concept in the following. The idea is to switch engine operation to a so-called 3/4-cylinder concept, meaning that one out of four cylinders can be deactivated. In 3-cylinder operation, one cylinder simply works as a gas spring (with all valves deactivated), so that most of the compression work will be returned to the process. With this concept, the disabled cylinder is no longer taking part in the gas exchange, effectively reducing efficiency loss due to charge exchange. The second benefit of HDMK is the reduction of wall heat losses. While one cylinder is deactivated, the remaining three cylinders undergo a load point shift to provide the same effective power to the engine. Although the internal cylinder temperature increases, wall heat transfer will effectively be reduced due to the reduced surface available for wall heat transfer in three instead of four cylinders $[4,5]$.

The fourth cylinder is employed to provide full power when needed, but typically only used for short time intervals. Consequently, the engine has been optimized from the point of engine mechanics for running in 3-cylinder mode. The firing order is changed to 4(1)-2-3 with a firing interval of 0-240-240$240^{\circ} \mathrm{KW}$. Cylinder 1 and 4 are running parallel. Figure 1 shows the modified crankset. Changing firing order also requires the adaption of the valve train layout. In order to realize this concept, a completely new cylinder head has been designed, which also allows additional measures for engine optimization [4].
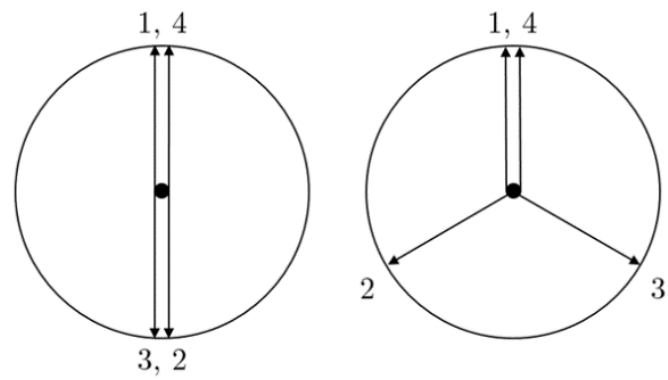

FIGURE 1: LEFT: CRANKSET OF BASIC ENGINE; RIGHT: HDMK CRANKSET

\section{CONCEPT OF CYLINDER HEAD}

In order to realize the 3/4-cylinder-concept, it is necessary to equip a variable valve train for the deactivation of cylinder 1 . The basic John Deere engine uses an OHV arrangement with the camshaft positioned in the engine block, using pushrods and rocker arms for valve actuation. To maximize the variability in valve timing, it was decided to use a fully variable valve train. The installation space for the series camshaft in the engine block is not sufficiently large for integrating a fully variable valve train. Also, the pushrods activate both exhaust or inlet valves of one cylinder. This does not allow the separate activation of one exhaust or inlet valve as desired. A double overhead camshaft (DOHC) is necessary to obtain this variability. Figure 2 shows a cut-off of the HDMK cylinder head with DOHC and the fully variable valve train (the timing chain is not shown). The detailed mechanism of the HDMK valve train is shown in Figure 3. 


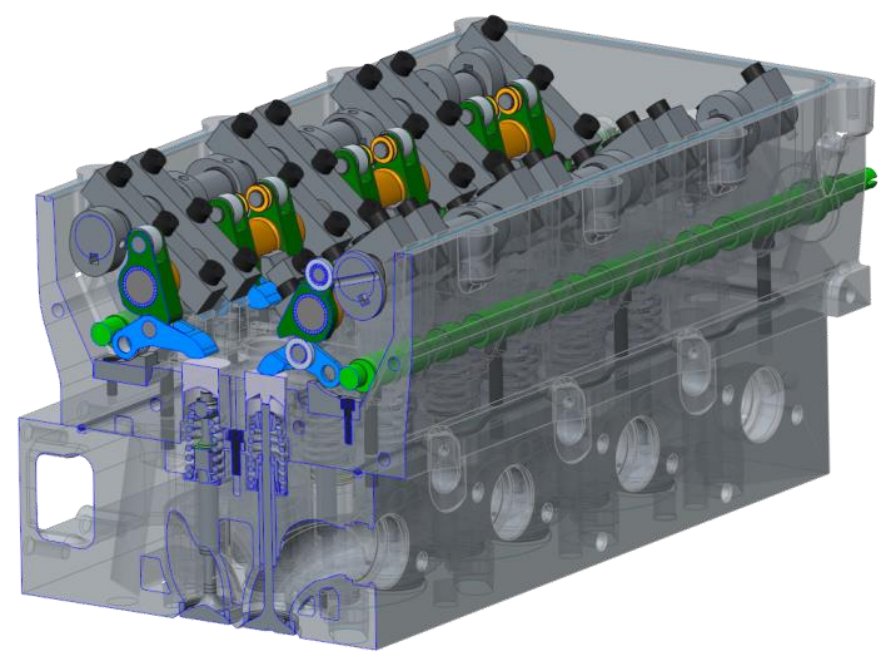

FIGURE 2: HDMK VALVE TRAIN

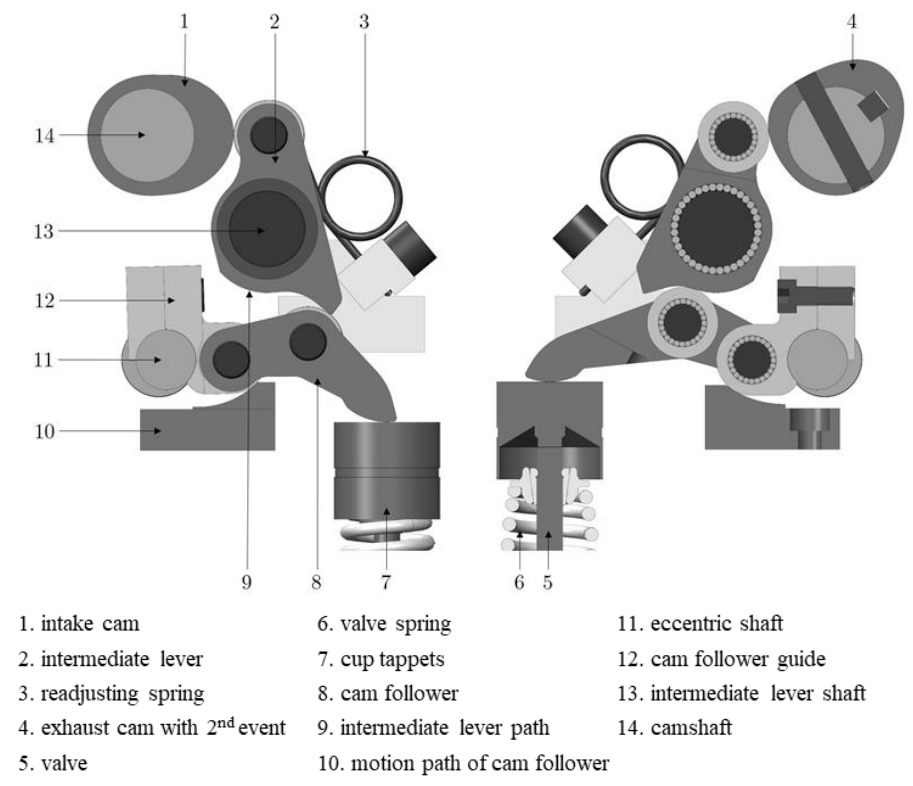

FIGURE 3: HDMK VALVE TRAIN MECHANISM (PROCAM@)

The variation of valve timing is realized by moving the cam follower (No. 8 in Fig. 3). One end of the cam follower carries out a simple translational motion across the cup tappets. The other end carries out a defined path motion (No. 10 in Fig. 3), so that the cam follower roller follows the zero-lift area of the intermediate lever path (No. 9 in Fig. 3). With each rotation of the camshaft, the cam follows the deflection of the intermediate lever. Its zero-lift area rotates around its axis until the (non-zero) lift area begins. In the lift area, the intermediate lever transmits the cam lift to the cam follower by its roller.

To reach full variability in the valve train, it was necessary to modify the valve positions in the cylinder head. As a consequence of this modification, a re-design of the inlet and exhaust ports also had to be carried out.

\section{POTENTIAL OF CYLINDER HEAD OPTIMIZATION USING EXAMPLE OF INLET PORTS}

The variation of valve timing can be used for different effects, e.g.:

- Second event: additional valve lift during the four-stroke cycle; e.g. exhaust valve opening during intake for internal exhaust gas recirculation (iEGR).

- Activation or deactivation of one or more cylinders.

- Inlet phasing: separate actuation of the inlet valves of one cylinder, e.g. with a delay of open time; used for influencing in-cylinder flow, e.g. varying swirl intensity (- combined with a second event, exhaust valve phasing can be used for dosing iEGR, or also for influencing in-cylinder flow).

- Early or late valve events for realizing Miller/Atkinson cycles or for controlling residual gas (e.g. by negative valve overlap).

To make these valve events possible, each valve has to be activated independently from the other valves of a cylinder. With the original John Deere cylinder head, the inlet and exhaust valve positions were located on the left and the right side with respect to the engine's longitudinal axis. For actuating the intake and exhaust valves independently from each other, separate cams and camshafts are necessary, which requires a change in valve position as displayed in Figure 4.
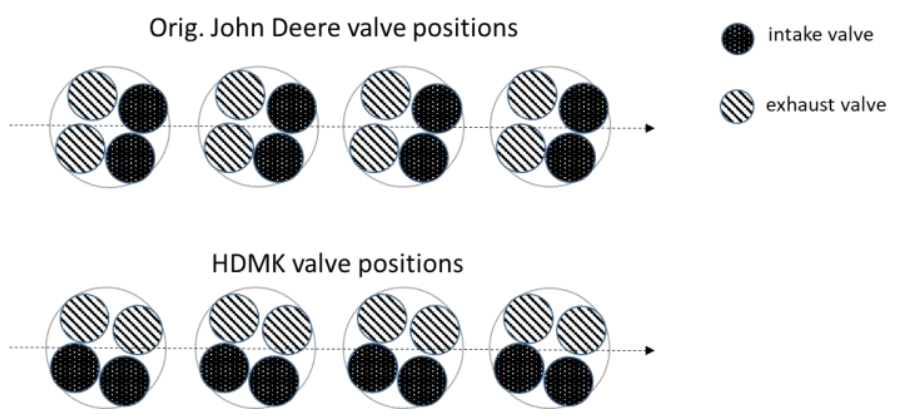

FIGURE 4: VALVE POSITIONS

The discharge ports were re-designed for the new HDMK valve positions. This optimization was based on the idea of maximizing the attainable flow rate while maintaining a homogeneous swirl distribution inside the cylinder.

For the port design, a parametric model was generated. It allows the modification of the port surface by customizing the paths of its surface mesh. This method allows to easily generate a large number of port geometries. The CFD simulation was carried out using AVL Fire, computing the discharge coefficient and swirl number, and also visualizing the 3D flow phenomena. These results were used to control the parametric model in order to generate ports with the desired characteristics. The optimal geometry is obtained through an iterative process. The known values of discharge coefficient and swirl number of the original John Deere cylinder head were used for validating the CFD simulation. Figure 5 shows the results of the steady state simulation for discharge coefficients and swirl numbers, compared to the values for the original John Deere cylinder head. 


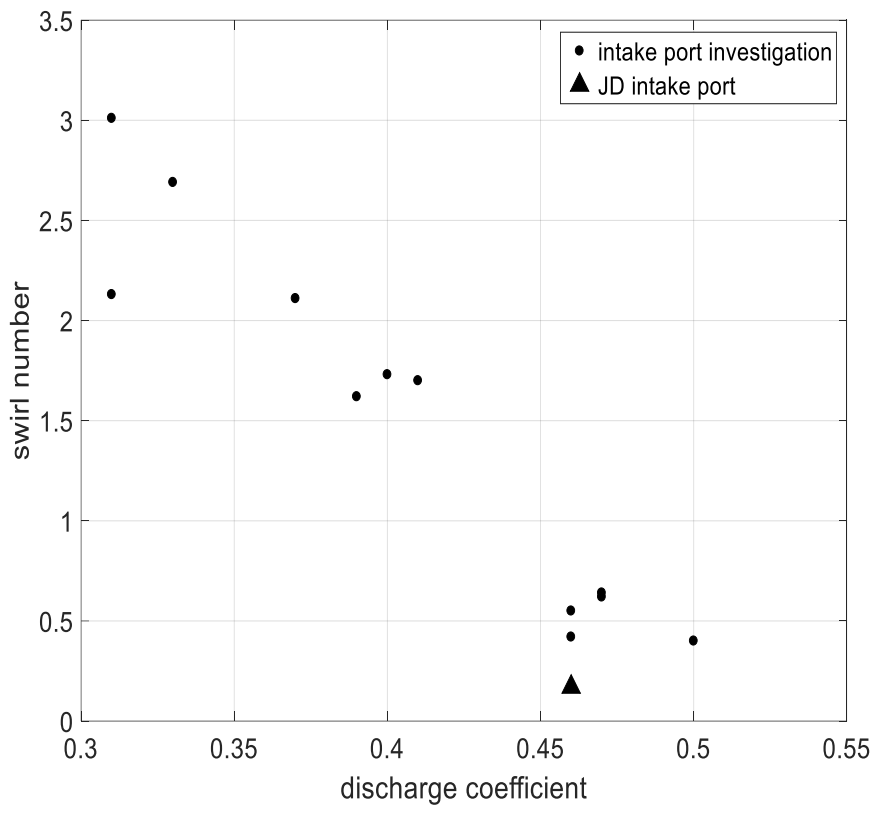

FIGURE 5: TRADE-OFF OF DISCHARGE COEFFICIENT VS. SWIRL NUMBER (STEADY-STATE SIMULATION)

The results show the trade-off of discharge coefficient vs. swirl. As obvious from the plot, it is possible to reach higher flow coefficients than the original ports in combination with an increased swirl number. Generally, large bore diesel engines do not require high swirl numbers for spray breakup as the injected fuel has more time for vaporization before it reaches the wall due to the larger the cylinder diameter [6 in German]. Therefore, the ports with maximum flow were selected in order to reduce the discharge losses.

The validation was continued by carrying out transient simulations of gas exchange. For these calculations, only the port designs with high discharge coefficients were selected. The 2D plot of the transient results depicted in Figure 6 confirms the increase of swirl number for all of the cases. The $3 \mathrm{D}$ results of the newly generated ports showed a homogeneous swirl distribution in the cylinder, which was even better in comparison to the series layout.

The inlet and exhaust ports were generated using same principle as described above. All results showed a rise of uniformity in flow distribution and a decrease of flow resistance.

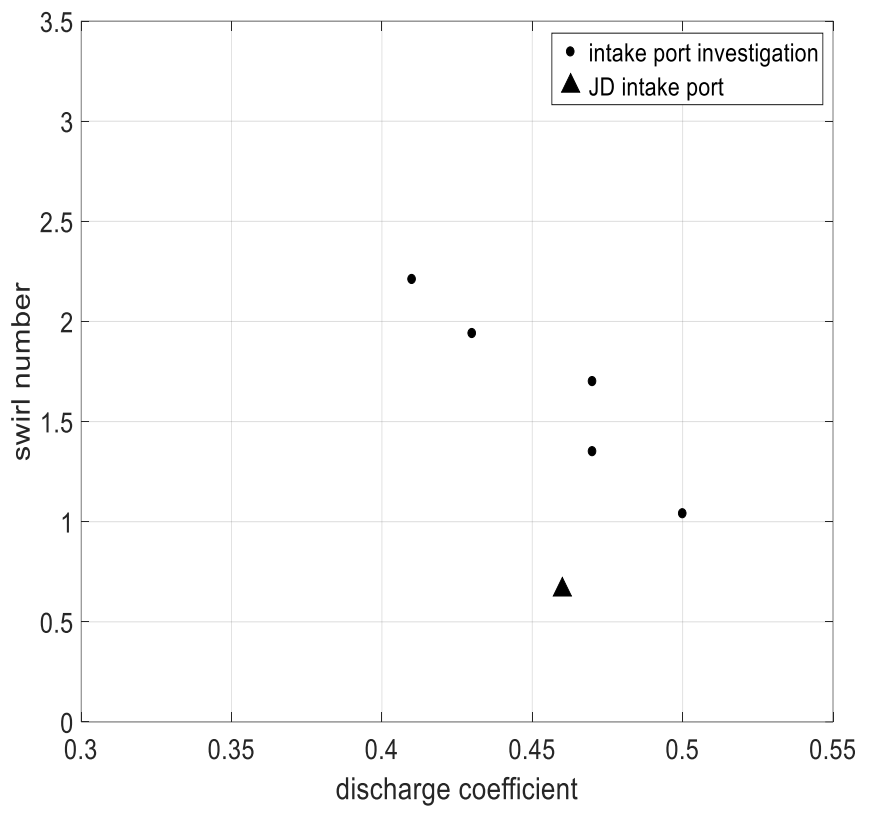

FIGURE 6: TRADE-OFF OF DISCHARGE COEFFICIENT VS. SWIRL NUMBER (TRANSIENT SIMULATION)

\section{ENGINE TEST BENCH RESULTS OF HDMK}

The HDMK engine is capable of deactivating cylinder 1 and also of realizing a second opening event of the exhaust valves of cylinder 2-4 during intake for recirculating residual gas. The valve train and the new cylinder head were designed to allow a variation of these operating cases. Before employing the variable valve train, a preliminary test with the modified firing order was carried out. For this test, cylinder 1 was deactivated by dismounting its pushrods and rocker arms for 3-cylinder operation. For the 3/4-cylinder operating mode, a cylinder activation line (CAL) is determined. Above this line, the 4cylinder mode is more efficient and will therefore be used. The comparison of the specific fuel consumption map of the 3/4cylinder and basic engine is shown in Figure 7.

In 4-cylinder mode, fuel consumption of the 3/4-cylinder engine is up to $2 \%$ higher when compared to the basic engine. While this mode will only be used for short-term power peaks, the more interesting map area is that of the 3-cylinder operating mode. In the most relevant area of the map, a reduction of fuel consumption of up to $8 \%$ could be reached (e.g. at $2000 \mathrm{rpm} /$ $200 \mathrm{Nm}$ ). Figure 7 also shows relevant areas of the operating map with up to $14 \%$ fuel consumption reduction. 


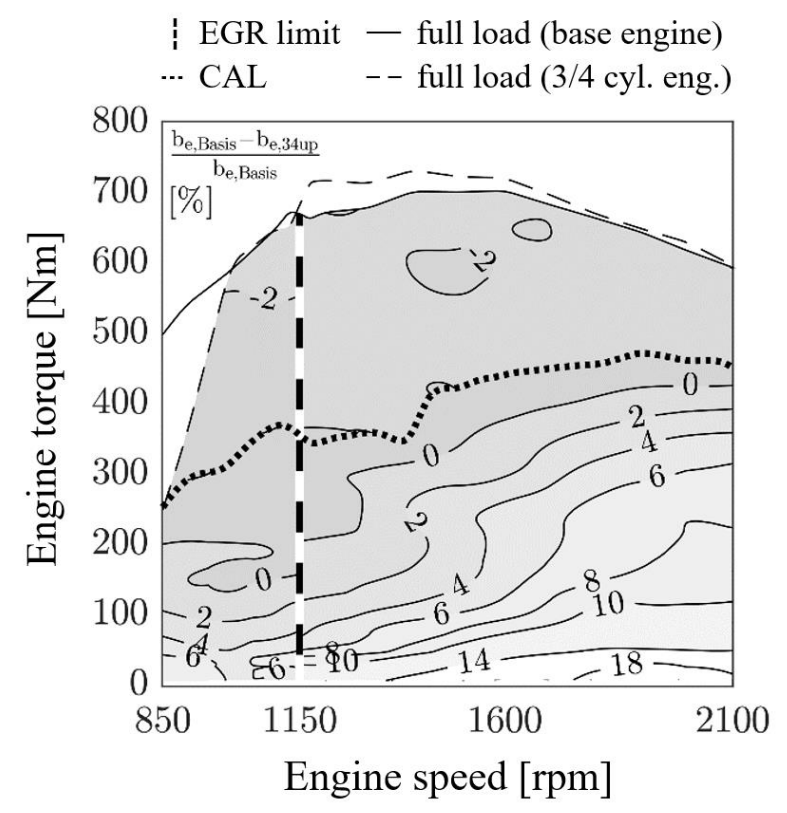

FIGURE 7: IMPROVEMENT OF SPECIFIC FUEL CONSUMPTION BY 3/4-CYLINDER OPERATION

To explain the deviation between the basic engine BSFC and the 3/4-cylinder engine BSFC, an efficiency analysis was carried out. The efficiency losses were calculated by $1 \mathrm{D}$-simulation. The model was calibrated using indicated pressure traces, injection timings, temperatures and exhaust gas composition. The operating point of $2000 \mathrm{rpm}$ and $200 \mathrm{Nm}$ was used to compare the basic engine with the 3-cylinder operating mode, whereas the operating point at $2000 \mathrm{rpm}$ and $500 \mathrm{Nm}$ was used for comparison of the 4-cylinder operating modes. the results of these efficiency analyses are displayed in Figure 8 and 9.

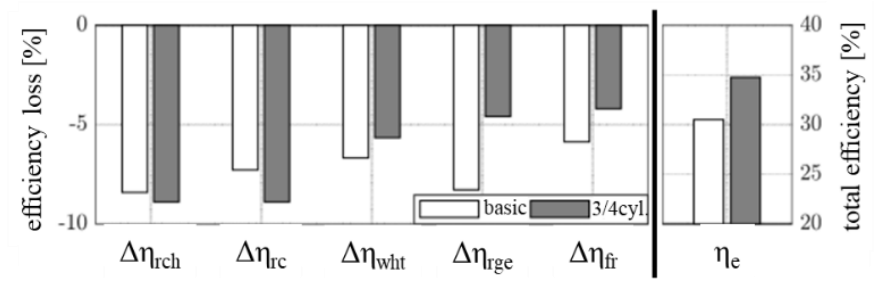

FIGURE 8: COMPARISON OF BASIC ENGINE WITH 3CYLINDERMODE@2000 RPM, 200 NM

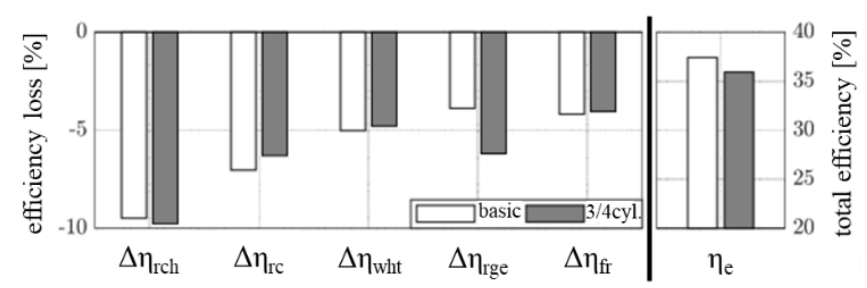

FIGURE 9: COMPARISON OF BASIC ENGINE WITH 4CYLINDERMODE@2000 RPM, 500 NM
The comparison displayed in Figure 8 shows a reduction especially of gas exchange loss in 3-cylinder operating mode. Besides, also friction and wall heat losses are reduced. In contrast, the 4-cylinder mode of the 3/4-cylinder layout exhibits increased gas exchange losses (Figure 9). This is the result of cylinder 1 and 4 operating in parallel. In Figure 10 the chargecycle loops of cylinder 4 for the basic engine and the 3/4-cylinder operating mode are compared to the charge-cycle loop of cylinder 3 in 3/4-cylinder operating mode. The increased chargecycle loop due to parallel exhaust of two cylinders explains the increased gas exchange losses of the 3/4-cylinder concept in 4cylinder operation.

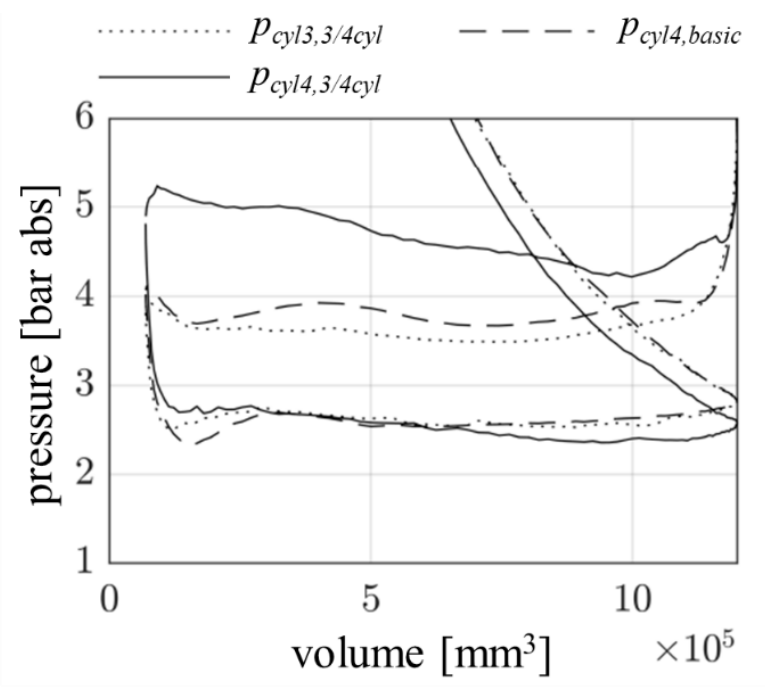

FIGURE 10: CHARGE-CYCLE OF BASIC ENGINE CYL4, 3/4CYLINDER CYL3 AND $4 @ 2000$ RPM, 500 NM

The results of Figure 8 and 9 also show that the efficiency losses of real charge and real combustion are not relevant for the increased efficiency of the 3-cylinder operating mode, nor for the reduced efficiency of 4-cylinder operating mode.

When the 3/4-cylinder mode is combined with the variable valve train, it is possible to investigate the effects of the second event of the exhaust valves. The relevant values here are nitrogen oxide emission $\left(\mathrm{NO}_{\mathrm{x}}\right)$ and exhaust temperature. Figure 11 shows a variation of the second event valve lift with and without additional external EGR.

The results show an increase of exhaust temperature and a reduction of $\mathrm{NO}_{\mathrm{x}}$ emissions. When using the second event in combination with external EGR, a further reduction of $\mathrm{NO}_{\mathrm{x}}$ emission and increase of exhaust temperature is possible, as represented by the dotted lines. The temperature increase caused by the second event can be used for regeneration procedures or for cold start heat up. It should be noted that the recirculation of residual gas by the second event slightly increases soot emissions due to the reduction of the mass of fresh air delivered to the cylinder. 


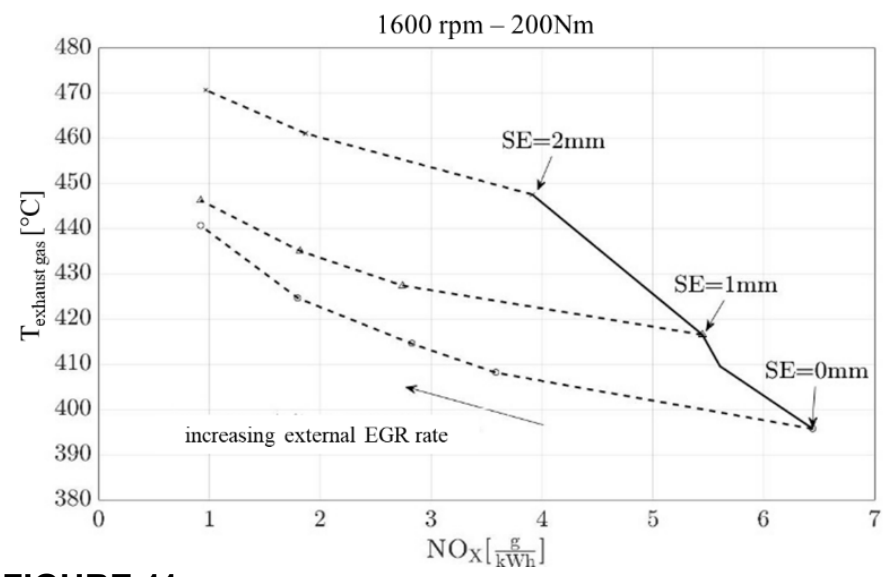

FIGURE 11: EFFECT OF SECOND EVENT OF THE EXHAUST VALVES ON NO${ }_{x}$ EMISSION AND EXHAUST TEMPERATURE

\section{VEHICLE INTEGRATION OF THE HDMK ENGINE}

In order to estimate the consumption savings of HDMK in real tractor operation, the DLG PowerMix test environment is used [7]. DLG PowerMix contains 12 field cycles, each of them representing a characteristic load requirement for a tractor engine. Table 3 shows the consumption savings of the 3/4cylinder concept compared to a John Deere series tractor with the same nominal power in the DLG PowerMix cycles. The load requirements of the individual cycles determined on the engine control unit form the basis of the following calculations.

The values of the last column represent the attained fuel consumption reduction, positive values indicating lower consumption of the HDMK engine. The advantages of the concept can clearly be found at lower and intermediate loads. For the high load cycles, slight disadvantages can be observed. On average across all cycles, HDMK realizes $1 \%$ fuel consumption benefit in comparison to the original John Deere tractor. If the tractor is not only used for pulling, the results of cycles $\mathrm{Z} 3 \mathrm{~K}$ to Z7PR are showing an advantage of $2 \%$ in favour of HDMK. The most significant consumption improvement of $5.2 \%$ is reached in the $\mathrm{Z5K}$ cycle. This cycle primarily uses the most efficient areas of the HDMK engine map.

For the final validation of these results, it is necessary to integrate the HDMK engine into a real tractor. The installation space for the engine is very confined. In order not to restrict functionality, such as the steering wheel angle or the driver's field of vision, the installation space must not be extended by modifications of the vehicle body.

\begin{tabular}{|l|l|l|l|l|}
\hline \multicolumn{2}{|l|}{ cycle } & $\begin{array}{l}\text { mean } \\
\text { engine } \\
\text { speed } \\
{[\mathrm{rpm}]}\end{array}$ & $\begin{array}{l}\text { mean } \\
\text { engine } \\
\text { torque } \\
{[\mathrm{Nm}]}\end{array}$ & $\begin{array}{l}\text { Fuel } \\
\text { consumption } \\
\text { savings } \\
3 / 4 \text { cyl } \\
{[\%]}\end{array}$ \\
\hline Z1P & plough $100 \%$ & 1468 & 491 & $-1,9$ \\
\hline Z2P & plough $60 \%$ & 1186 & 418 & $-1,0$ \\
\hline Z1G & cultivate $100 \%$ & 1861 & 459 & $-0,5$ \\
\hline Z2G & cultivate $60 \%$ & 1384 & 438 & $-1,4$ \\
\hline Z3K & $\begin{array}{l}\text { rotary harrow } \\
100 \%\end{array}$ & 1667 & 460 & $-0,7$ \\
\hline Z4K & $\begin{array}{l}\text { rotary harrow } \\
70 \%\end{array}$ & 1712 & 352 & 0,8 \\
\hline Z5K & $\begin{array}{l}\text { rotary harrow } \\
40 \%\end{array}$ & 1735 & 249 & 5,2 \\
\hline Z3M & mowing $100 \%$ & 1728 & 477 & $-0,9$ \\
\hline Z4M & mowing $70 \%$ & 1706 & 403 & $-0,4$ \\
\hline Z5M & mowing $40 \%$ & 1730 & 297 & 3,9 \\
\hline Z6MS & manure spreading & 1896 & 398 & 1,2 \\
\hline Z7PR & bale wrapping & 1924 & 345 & 3,0 \\
\hline
\end{tabular}

TABLE 3: POTENTIAL OF HDMK IN DLG-POWERMIX

The new cylinder head with DOHC increases the height of the engine, which primarily reduces the installation space for the turbocharger, the exhaust pipe, the diesel particulate filter (DPF) and the air compressor. In addition to the test bench engine, a second engine was therefore designed for integration into the tractor. The cylinder head cover and the attached parts were redesigned to comply with the installation space. The turbocharger is installed flat under the hood. A new DPF with increased efficiency and thus reduced diameter is located beside it. The cylinder head cover is shaped as a "V" between the camshafts. With this configuration, it is possible to install the exhaust pipe between the turbocharger and the DPF inside the "V"-shaped opening. In addition to this, attached parts like the exhaust manifold, the eccentric shaft actuator housing or the turbocharger bracket also had to be adapted. A comparison of the basic engine and the HDMK engine installation space is shown in Figure 12. 

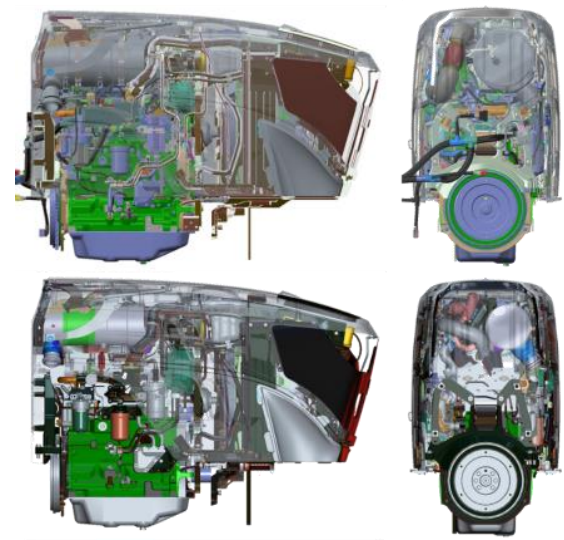

orig. John Deere

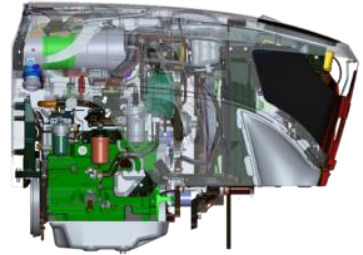

HDMK

FIGURE 12: COMPARISON OF INSTALLATION SPACE: ORIG. JD TRACTOR VS. HDMK ENGINE

The air compressor is positioned at the level of the V-ribbed belt. In this area, the cam phaser makes it necessary to raise the cylinder head cover more than in other areas. This also defines the mounting height of the air compressor, which is the reason why a cut in the frame of the hood is needed. Figure 13 shows the compressor position and the increased height of the HDMK engine. Figure 14 shows the picture of the final status of HDMK tractor with the new engine integrated in the engine compartment. The validation of the efficiency increase in real vehicle operation is currently in progress.

\section{orig. John Deere HDMK}

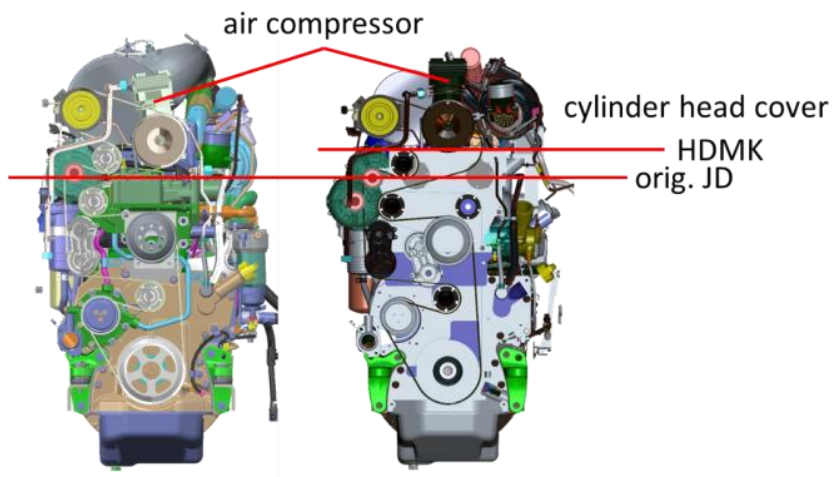

FIGURE 13: COMPARISON HEIGHT OF CYLINDER HEAD: JD VS. HDMK ENGINE

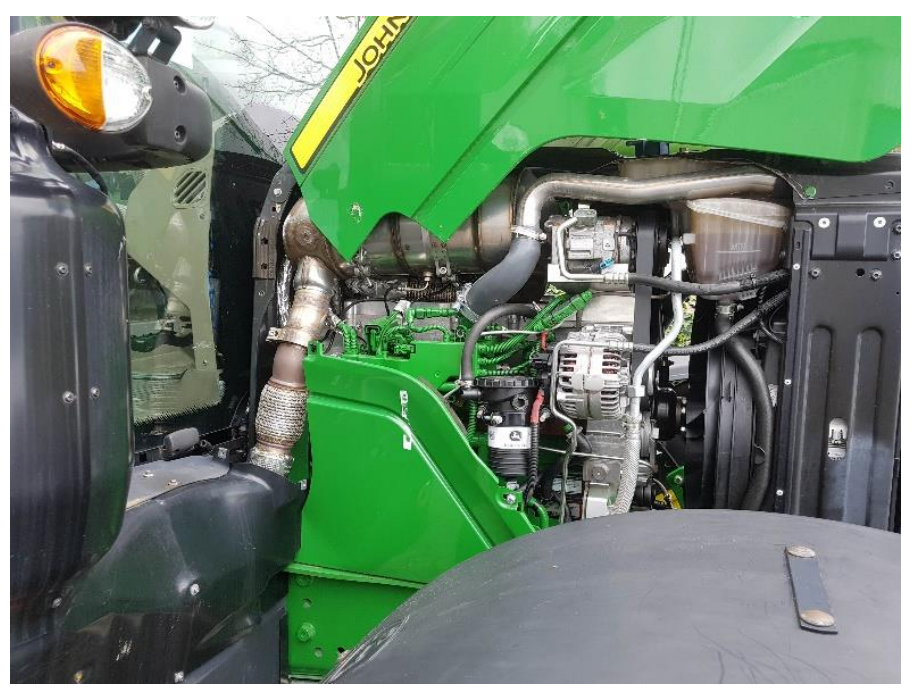

FIGURE 34: HDMK ENGINE INTEGRATED INTO THE JD TRACTOR

\section{SUMMARY}

The HDMK engine concept presented in this paper proved to be suitable for increasing efficiency at low and medium engine loads. The variable valve train both enables cylinder deactivation and the application of a second event of the exhaust valves, which can be used to increase the exhaust gas temperature by recirculating internal EGR.

The HDMK prototype engine with variable valve train and cylinder deactivation following the 3/4-cylinder principle was successfully integrated into a running tractor and satisfies all functions of a drive unit.

\section{ACKNOWLEDGEMENTS}

The authors acknowledge the financial support by the German Federal Ministry for Economic Affairs and Energy.

Supported by:

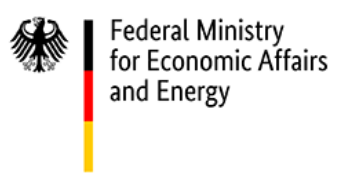

on the basis of a decision by the German Bundestag 


\section{REFERENCES}

[1] European Commission, $\operatorname{COM(2018)773,~A~clean~planet~}$ for all: A European long-term strategic vision for a prosperous, modern, competitive and climate neutral economy, Brussels, 2018

[2] Internet: https://www.deere.co.uk/en/tractors/mid/6mseries/6135m, Download: 05/03/2019

[3] Europäisches Parlament und Rat, RICHTLINIE 2004/26/EG DES EUROPÄISCHEN PARLAMENTS UND DES RATES, 21. April 2004

[4] Schurr A., Guenthner M., Flierl R., Investigation of Cylinder Activation Concept for a Turbocharged DirectInjection Gasoline Engine, SAE techn. paper no. 2018-01-1713, Heidelberg, 2018

[5] Neugaertner J., Scholz A., Schurr A., Guenthner M., Flierl R., Load point shifting for Diesel engines - potentials for passenger car and truck engine applications, VDI/ATZ International Engine Congress, Baden-Baden, 2017

[6] Eisen S.-M., Visualisierung der dieselmotorischen Verbrennung in einer schnellen Kompressionsmaschine [Visualization of Combustion in a Rapid Compression Machine], Ph.D. Thesis, Technical University of Munich (TUM): Chair of Thermodynamics, 2003 [in German]

[7] Internet: https://www.dlg.org/en/agriculture/testsagriculturel testing-fields/vehicle-technology-and-electronics, Download: 05/03/2019 